\title{
A Study of Concrete Made with Fine and Coarse Aggregates Recycled from Fresh Concrete Waste
}

\author{
Mamery Sérifou, ${ }^{1,2}$ Z. M. Sbartaï, ${ }^{1}$ S. Yotte, ${ }^{3}$ M. O. Boffoué, ${ }^{2}$ E. Emeruwa, ${ }^{2}$ and F. Bos ${ }^{1}$ \\ ${ }^{1}$ University of Bordeaux, I2M, Department of GCE, CNRS, INRA, 351 Cours de la Libération, Bâtiment A 11, \\ 33405 Talence Cedex, France \\ ${ }^{2}$ University of Félix Houphouët Boigny, Laboratoire Géomatériaux et Technologie de l'Habitat, \\ 01 BP V34 Abidjan 01, Cote d'Ivoire \\ ${ }^{3}$ Limoges University, GEMH, Centre Universitaire de Génie Civil, boulevard Jacques Derche, 19300 Égletons, France
}

Correspondence should be addressed to Z. M. Sbartaï; zm.sbartai@i2m.u-bordeauxl.fr

Received 26 February 2013; Revised 27 May 2013; Accepted 15 July 2013

Academic Editor: Anaclet Turatsinze

Copyright (C) 2013 Mamery Sérifou et al. This is an open access article distributed under the Creative Commons Attribution License, which permits unrestricted use, distribution, and reproduction in any medium, provided the original work is properly cited.

\begin{abstract}
This paper deals with the possibility of using fresh concrete waste as recycled aggregates in concrete. An experimental program based on two variables (proportion of fine aggregates replacement and proportion of coarse aggregates replacement) was implemented. The proportions of replacement were $0 \%, 50 \%$, and $100 \%$ by mass of aggregates. Several mechanical properties were tested as compressive and tensile strengths. The results show a good correlation between aggregates replacement percentage and concrete properties. Concerning mechanical properties, a gradual decrease in compressive, splitting, and flexural strengthn with the increase in recycled aggregate percentage is shown.
\end{abstract}

\section{Introduction}

The intensive use of aggregates in constructions is a very important environmental concern. In the region of Aquitaine in France, the availability of aggregates becomes a serious problem. In order to reduce the use of natural aggregates for natural resources and energy preservation, the use of recycled aggregates in concretes is an interesting solution.

Numerous studies show the potential of recycling aggregates such as ceramics [1], rubber [2,3], glass [4], and demolition wastes (bricks and concrete). Due to the high amount of concrete from demolition wastes, this material was studied as substitution of natural aggregates by several authors [5-8]. However, these aggregates are highly porous, and contain a high amount of impurities [8,9]. Limited studies were conducted on the potential of fresh concrete waste (FCW). These aggregates are mainly composed of overordered fresh concrete. The advantage of this waste is that it contains limited amount of impurities in comparison with other recycled aggregates.

Every day, a concrete batching plant receives from several construction sites a huge amount of overordered fresh concrete. This is caused mainly by the uncertainty in the exact quantity of the required concrete for construction projects. In France, 2.6 million tons of fresh concrete is considered as waste and should be recycled. Currently, the practice of managing overordered fresh concrete is to use it in road or to dump it into landfill, which is considered as a nonbenefit solution. Moreover it will be of high cost in the close future because of the saturation of landfill areas [10].

Recycling this material is of particular interest because its use can considerably reduce the problem of waste storage, and simultaneously it helps in the preservation of natural aggregate resources. Recent successful studies on the use of FCW as aggregates in concrete have been reported [11, 12]. The results of these studies show that the compressive strength and the slump decrease with increasing the FCW aggregates percentage. However, they are mainly devoted to experiences with crushed concrete as coarse aggregates. Therefore, there is a lack of knowledge about the behaviour of concrete made with fine fraction (grain size $<5 \mathrm{~mm}$ ) or coarse and fine aggregates of fresh concrete waste.

In this study, concrete mixes with fine and coarse aggregates recycled from fresh concrete waste as a substitution of 


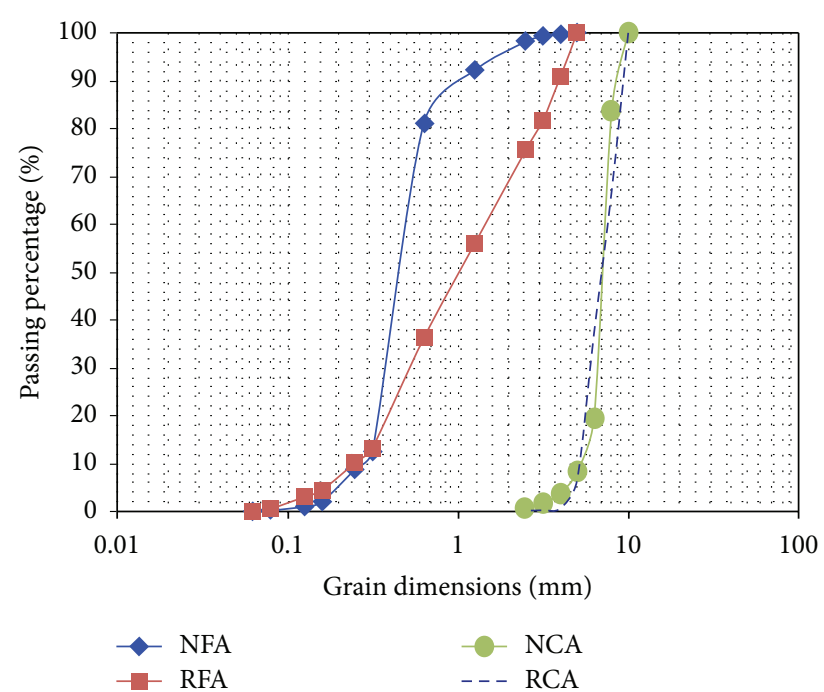

FIGURE 1: Grain size distribution of natural and recycled aggregates.

natural aggregates are studied. Optimised design of experiment was used with two variables (rates of fine aggregate replacement or of coarse aggregate replacement) on the basis of identical composition. Mechanical test results are presented and discussed.

\section{Experimental Study}

2.1. Materials. The used materials are natural coarse aggregates (NCA), recycled coarse aggregates (RCA), natural fine aggregates (NFA), and recycled fine aggregates (RFA). The recycled aggregates are crushed from the same fresh concrete waste (FCW) after one month of curing. Portland cement CEM II32.5 $\mathrm{R}$ is used. Figure 1 presents the grain size distribution of the natural and recycled aggregates. From Figure 1, the grain size distribution of natural and crushed aggregates is comparable. However, FRA are coarser which could reduce the work ability of concrete made with these fine aggregates. Recycled aggregates present relatively lower density (mainly in the case of RFA) and higher water absorption compared to natural aggregates as can be seen in Table 1 . Water absorption is particularly high in the case of RFA (13\% against $1.6 \%)$.

2.2. Mix Design. In order to limit the number of mixes and for a comparative study based on common references, the work ability is fixed constant (slump $=70 \pm 20 \mathrm{~mm}$ ). The experimental program was implemented based on two variables: percentage of fine aggregates $(0-5 \mathrm{~mm})$ and the percentage of coarse aggregates $(5-10 \mathrm{~mm})$. The proportion of replacement was $0 \%, 50 \%$, and $100 \%$ by mass for both aggregates. The optimal number of mixes was calculated using design of experiment method $\left(2^{n}\right)$, with $n$ the number of studied factors (two in the case of this study) [11]. The first factor is the percentage of RCA, and the second factor is the percentage of RFA. This experimental program of 4 experiences is used for $0 \%$ and $50 \%$ of substitution and for $0 \%$
TABLE 1: Aggregates characteristics.

\begin{tabular}{lcccc}
\hline Characteristics & NFA & RFA & NCA & RCA \\
\hline d/D (mm) & $0 / 5$ & $0 / 5$ & $5 / 10$ & $5 / 10$ \\
Fineness (\%) & 2.2 & 3.2 & - & - \\
Density & 2.7 & 2.4 & 2.6 & 2.6 \\
Absorption (\%) & 1.6 & 13 & 1.5 & 4.3 \\
\hline
\end{tabular}

and $100 \%$ of substitution. Table 2 summarize the percentage of substitution for the experimental design.

The concrete composition considered as the reference is an Ordinary Portland Concrete of 25/30 class of strength. Recycled concrete composition is the same as the reference concrete mixture. However, because of the high water absorption of recycled aggregates, water proportion was adjusted to reach the desired work ability. The volume of water added to the mixes made with $100 \%$ of RFA is 78.391 , which corresponds to $44 \%$ of the total quantity of water. For the mixture made with $100 \%$ RCA, the water is increased only by $20 \%$. The volume of added water of RFA is then higher than RCA. This can be explained by the fact that water absorption of RFA is higher than RCA. In the case of $100 \%$ substitution of both aggregates, the necessary increased water is about $56 \%$ as can be seen in Table 2 . These corrections will drastically influence the strength of concrete, but, without plasticiser, water correction is needed to reach the desired work ability.

2.3. Casting, Curing, and Testing. Mechanical properties of the concrete mixes were tested at 1,14 , and 28 days. For each mix, three cylinders of $16 \times 32 \mathrm{~cm}^{2}$ in size, six cylinders of $11 \times 22 \mathrm{~cm}^{2}$, and three flexure beams of size $7 \times 7 \times 28 \mathrm{~cm}^{3}$ were cast and compacted by vibrating machine. The specimens were kept in laboratory ambient temperature for 24 hours. After 24 hours, the specimens were placed in water for 28 days of curing. Cylindrical samples with $16 \mathrm{~cm}$ and $11 \mathrm{~cm}$ diameter were used, respectively, for compressive tests and tensile strength measurement by splitting test. In comparison with splitting test, flexural strength was tested with prismatic beams using three-point bending.

\section{Results and Discussion}

The compressive strengths for all mixes of 1,14 , and 28 days of curing are presented in Table 3 . The results show that the higher the replacement by recycled aggregates, the lower the compressive strength for all the curing durations. These results are in agreement with Correia et al. [11] and Kou et al. [12]. Both coarse and fine recycled aggregates decrease the compressive strength. Typical results for the relationship between compressive strength and curing time are presented in Figure 2. The results concern mixes with RFA. All the tested mixes present a decrease in strength. This is mainly due to the added water for the work ability correction. However, the compressive strength of young concrete, typically after 1 day of curing, is more influenced by the incorporation of recycled aggregates than the mixes tested after 14 and 28 days. This is in agreement with the results of Kou et al. [7] who 
TABLE 2: Design of experiments and mixtures proportions.

\begin{tabular}{|c|c|c|c|c|c|c|c|}
\hline & Mixl & Mix2 & Mix3 & Mix4 & Mix5 & Mix6 & Mix7 \\
\hline RFA (\%) & 0 & 0 & 50 & 50 & 0 & 100 & 100 \\
\hline RCA (\%) & 0 & 50 & 0 & 50 & 100 & 0 & 100 \\
\hline Total of recycled aggregates (\%) & 0 & 25 & 25 & 50 & 50 & 50 & 100 \\
\hline CEM II $32.5 \mathrm{R}\left(\mathrm{kg} / \mathrm{m}^{3}\right)$ & 385 & 385 & 385 & 385 & 385 & 385 & 385 \\
\hline NFA $\left(\mathrm{kg} / \mathrm{m}^{3}\right)$ & 627 & 627 & 314 & 314 & 618 & - & - \\
\hline $\operatorname{RFA}\left(\mathrm{kg} / \mathrm{m}^{3}\right)$ & - & - & 314 & 314 & - & 856 & 823 \\
\hline $\operatorname{RCA}\left(\mathrm{kg} / \mathrm{m}^{3}\right)$ & - & 574 & - & 574 & 1109 & - & 840 \\
\hline $\operatorname{NCA}\left(\mathrm{kg} / \mathrm{m}^{3}\right)$ & 1147 & 574 & 1147 & 574 & - & 860 & - \\
\hline Water (L) & 178 & 178 & 178 & 178 & 178 & 178 & 178 \\
\hline Water, corrected $(\mathrm{L})$ & - & 2.4 & 22.2 & 33.8 & 36.2 & 78.4 & 98.1 \\
\hline $\mathrm{w} / \mathrm{c}$ & 0.46 & 0.46 & 0.46 & 0.46 & 0.46 & 0.46 & 0.46 \\
\hline $\mathrm{w} / \mathrm{c}$, corrected & - & 0.47 & 0.52 & 0.55 & 0.56 & 0.67 & 0.72 \\
\hline
\end{tabular}

${ }^{*}$ The total of recycled aggregates (\%) is the percentage of the recycled aggregates with respect to the total masses of aggregates.

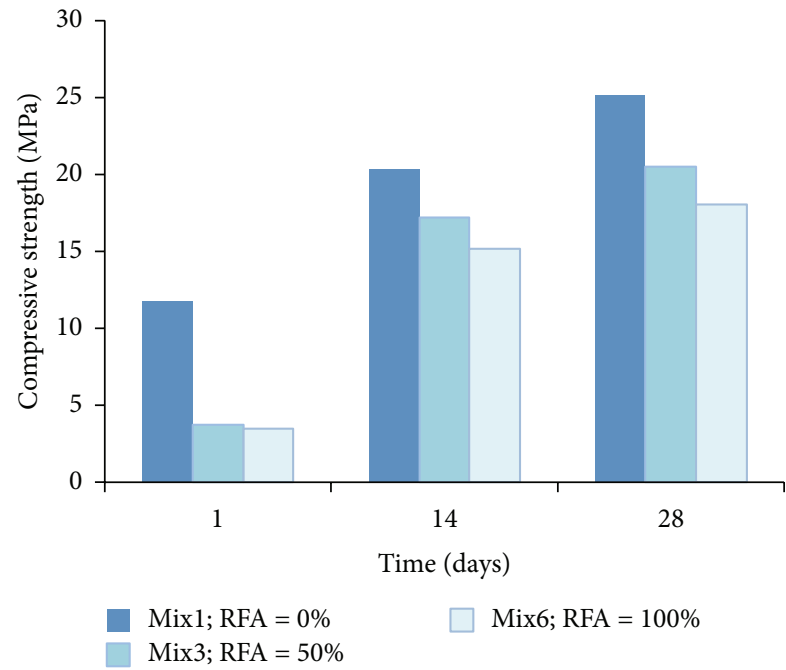

FIGURE 2: Compressive strength with respect to curing time for $0 \%$, $50 \%$, and $100 \%$ of RFA.

shows that the difference in compression strength between a natural aggregate concrete and a recycled aggregate concrete decreases with time.

The relationship between compressive strength and the percentage of the recycled fine and coarse aggregates at 28 days is presented in Figure 3. From these figures, the compressive strength decreases with increasing the percentage of recycled aggregates for RFA, RCA, and RFA + RCA. This is because the aggregates are a mix of aggregates and old mortar that increases the new concretes porosity. In addition, this porosity increases mainly in the transition zone between aggregates and the new mortar, which decreases the mechanical performances of concrete [13]. In fact, the aggregates crushed from FCW are composed of two parts: natural aggregate and old mortar (the old mortar is still wrapped around the natural aggregate after the crushing). Under loading, the crack should be created in the transition zone between aggregate and old mortar sooner than in other

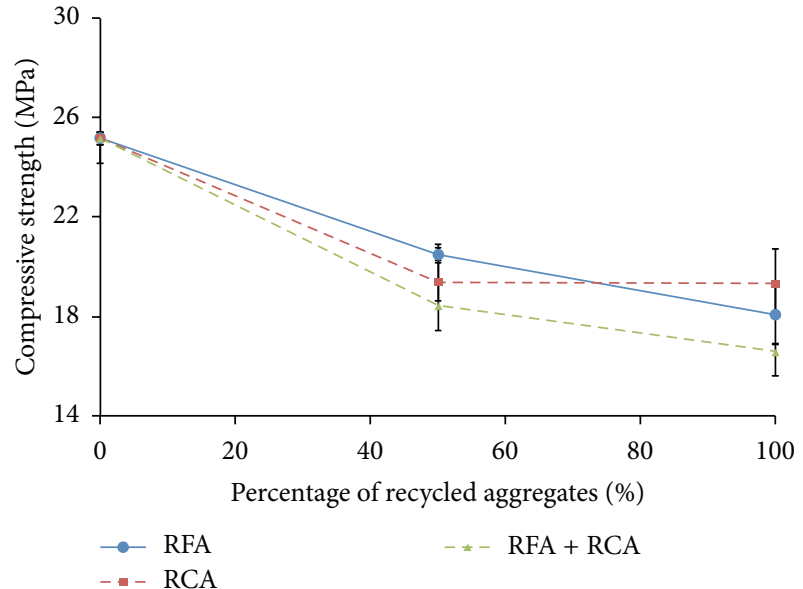

FIGURE 3: Effect of grain size on compressive strength at 28 days.

point of the new concrete. Moreover, the old mortar part has smaller compressive strength than the part of natural aggregate. The old mortar is then the weak point in the new concrete.

The effect of grain size is not significant because it is lower than the standard deviation of compressive strength measurement. For instance, in the case of mixes with $50 \%$ of recycled aggregates, the difference between RFA and RCA is of about 1.2 MPa whereas the standard deviation is of about 1.4 MPa for RCA and 0.8 MPa for RFA. Compressive strength is then not significantly affected by the grain size of recycled aggregates. However, at $100 \%$ replacement, a mix made with RCA gives $20 \%$ higher strength than a mix made with RFA.

As the grain size effect can be neglected, the compressive strength depends then only on the proportion of the recycled aggregates (fine or coarse) from FCW. As can be seen in Figure 4, the compressive strength shows only a 15\% decrease for $25 \%$ of aggregates replacement and 32\% decrease for $100 \%$ of aggregates replacement. These results show that it is possible to use $100 \%$ of recycled aggregates in application as, for example, pavements and concrete blocks. A high 
TABle 3: Compressive strength of the tested mixes at 1, 14, and 28 days.

\begin{tabular}{|c|c|c|c|c|c|}
\hline \multicolumn{3}{|c|}{$\%$ of recycled aggregates } & \multirow{2}{*}{1} & \multirow{2}{*}{14} & \multirow{2}{*}{28} \\
\hline & RFA & RCA & & & \\
\hline Mixl & 0 & 0 & 11.8 & 20.3 & 25.2 \\
\hline Mix2 & 0 & 50 & 3.7 & 17.2 & 20.5 \\
\hline Mix3 & 50 & 0 & 2.6 & 16.3 & 19.4 \\
\hline Mix 4 & 50 & 50 & 3.9 & 15.8 & 18.4 \\
\hline Mix5 & 0 & 100 & 3.5 & 15.2 & 18.1 \\
\hline Mix6 & 100 & 0 & 4.2 & 16.9 & 19.3 \\
\hline Mix7 & 100 & 100 & 3.5 & 14.9 & 16.6 \\
\hline
\end{tabular}

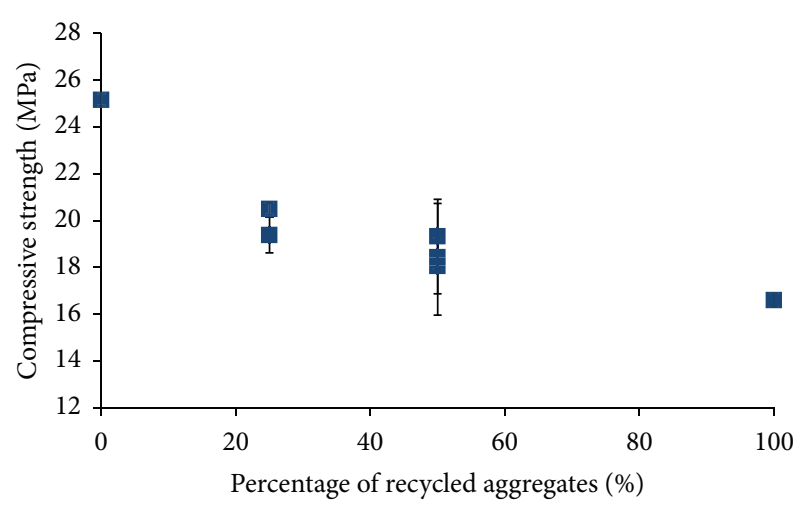

FIGURE 4: Relationship between compressive strength at 28 days and the proportion by mass of recycled aggregates.

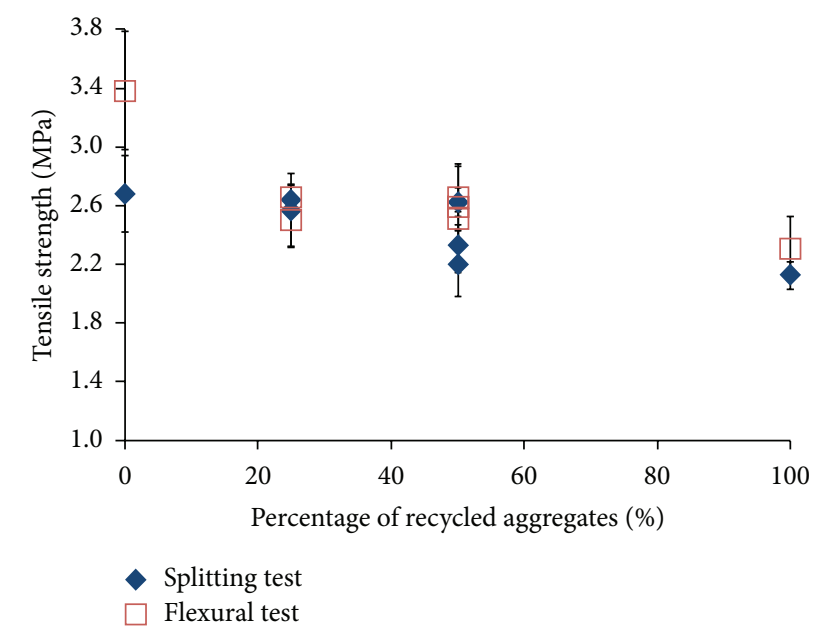

FIGURE 5: Relationship between tensile strength (splitting and bending tests) at 28 days and the proportion of recycled aggregates.

correlation exists between compressive strength and the total percentage of recycled aggregates. The behaviour is not linear but can be adjusted by a polynomial relation with $R^{2}=0.92$ :

$$
f_{c}=0.001 x^{2}-0.177 x+24.6
$$

where $f_{c}$ is the concrete compressive strength and " $x$ " the percentage of the total recycled aggregates.
The relationship between concrete tensile strength and the proportion of aggregates replacement is presented in Figure 5. In this figure, results of both splitting test and bending test are presented. A small decrease in the tensile strength can be seen. For 100\% aggregates replacement, the tensile strength measured by splitting test decreases by only $18 \%$. In the case of mix with $25 \%$ aggregates replacement, the tensile strength measured using splitting test is the same as the tensile strength measured using the bending test. For the other percentages of replacement (50\% and 100\%), the difference between bending and splitting test is not significant.

\section{Conclusions}

(i) Water absorption of the recycled fine and coarse aggregates from fresh concrete waste is higher than the naturel aggregates. The measured coefficient of absorption is $4.3 \%$ and $13 \%$ for coarse and fine aggregates, respectively.

(ii) The use of fresh concrete waste, after crushing, as recycled fine and coarse aggregates decreases the mechanical performance of the new concrete.

(iii) The compressive strength decreases gradually with respect to the increase of the percentage of recycled aggregates. This relationship can be approximated by a polynomial function with $R^{2}=0.92$. Moreover, this behaviour does not depend on the aggregates size for concrete made with aggregates size $<12.5 \mathrm{~mm}$.

(iv) The substitution of natural aggregates with $25 \%$, $50 \%$, and $100 \%$ of recycled aggregates decreases the compressive strength by about $15 \%, 25 \%$, and $32 \%$, respectively.

(v) The decrease in tensile strength is by $18 \%$ when $100 \%$ of the recycled aggregates are incorporated.

\section{Acknowledgments}

This study was supported by the DURATINET European Project (http://www.duratinet.org/). Cemex Company is acknowledged for its support. 


\section{References}

[1] A. R. Khaloo, "Properties of concrete using crushed clinker brick as coarse aggregate," ACI Materials Journal, vol. 91, no. 2, pp. 401-407, 1994.

[2] N. Segre and I. Joekes, "Use of tire rubber particles as addition to cement paste," Cement and Concrete Research, vol. 30, no. 9, pp. 1421-1425, 2000.

[3] A. Turatsinze, S. Bonnet, and J.-L. Granju, "Mechanical characterisation of cement-based mortar incorporating rubber aggregates from recycled worn tyres," Building and Environment, vol. 40, no. 2, pp. 221-226, 2005.

[4] I. B. Topçu and M. Canbaz, "Properties of concrete containing waste glass," Cement and Concrete Research, vol. 34, no. 2, pp. 267-274, 2004.

[5] J. M. V. Gómez-Soberón, "Porosity of recycled concrete with substitution of recycled concrete aggregate: an experimental study," Cement and Concrete Research, vol. 32, no. 8, pp. 13011311, 2002.

[6] T. Tu, Y. Chen, and C. Hwang, "Properties of HPC with recycled aggregates," Cement and Concrete Research, vol. 36, no. 5, pp. 943-950, 2006.

[7] S. Kou, C. Poon, and M. Etxeberria, "Influence of recycled aggregates on long term mechanical properties and pore size distribution of concrete," Cement and Concrete Composites, vol. 33, no. 2, pp. 286-291, 2011.

[8] R. Zaharieva, F. Buyle-Bodin, F. Skoczylas, and E. Wirquin, "Assessment of the surface permeation properties of recycled aggregate concrete," Cement and Concrete Composites, vol. 25, no. 2, pp. 223-232, 2003.

[9] R. Boder, Substitution des granulats alluvionnaires dans l'industrie du béton par les granulats marins, concassés ou recyclés, CERIB, Epernon, France, 2003.

[10] V. W. Y. Tam and C. M. Tam, "Economic comparison of recycling over-ordered fresh concrete: a case study approach," Resources, Conservation and Recycling, vol. 52, no. 2, pp. 208218, 2007.

[11] S. L. Correia, F. L. Souza, G. Dienstmann, and A. M. Segadães, "Assessment of the recycling potential of fresh concrete waste using a factorial design of experiments," Waste Management, vol. 29, no. 11, pp. 2886-2891, 2009.

[12] S. Kou, B. Zhan, and C. Poon, "Feasibility study of using recycled fresh concrete waste as coarse aggregates in concrete," Construction and Building Materials, vol. 28, no. 1, pp. 549-556, 2012.

[13] M. S. de Juan and P. A. Gutiérrez, "Study on the influence of attached mortar content on the properties of recycled concrete aggregate," Construction and Building Materials, vol. 23, no. 2, pp. $872-877,2009$. 

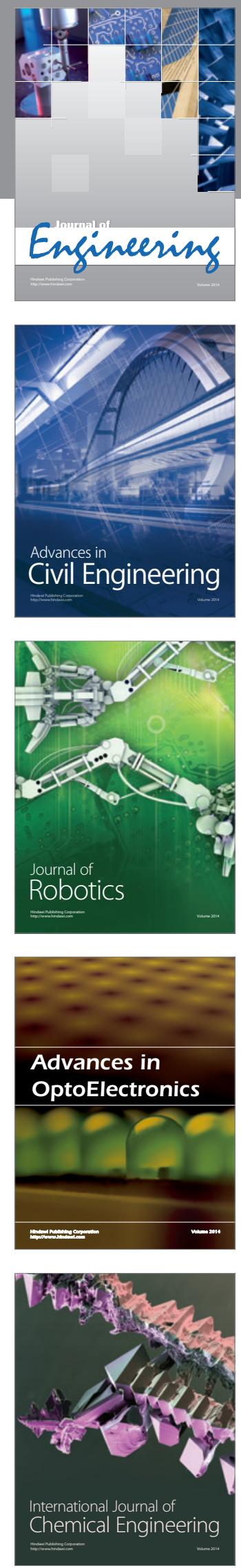

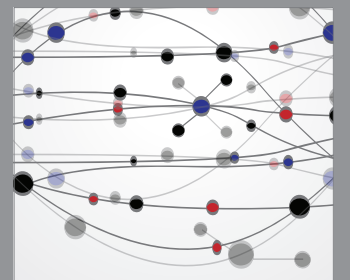

The Scientific World Journal
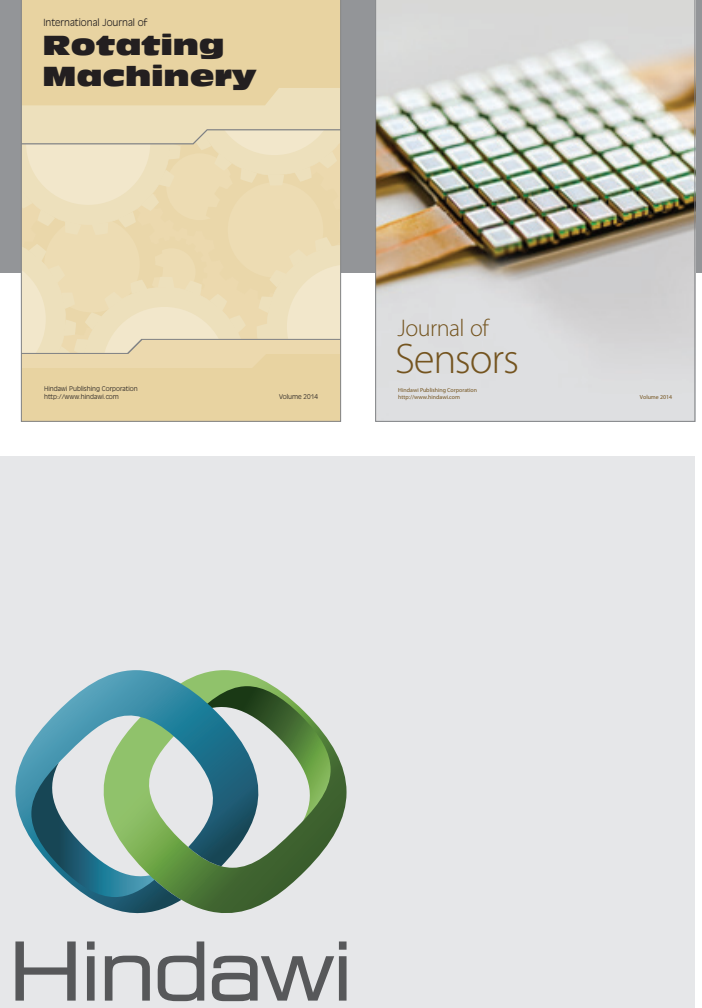

Submit your manuscripts at http://www.hindawi.com
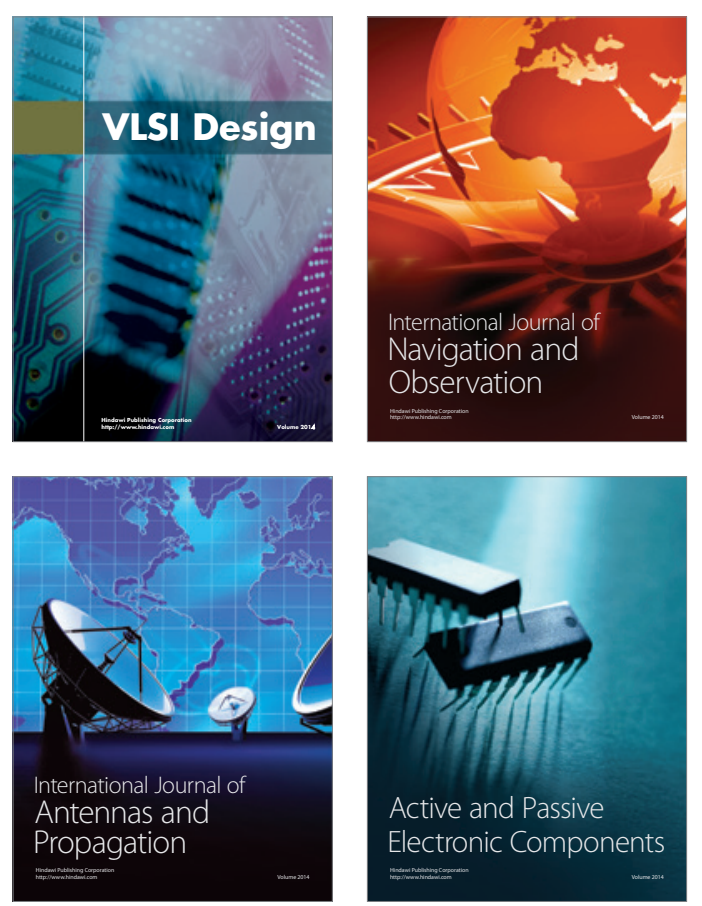
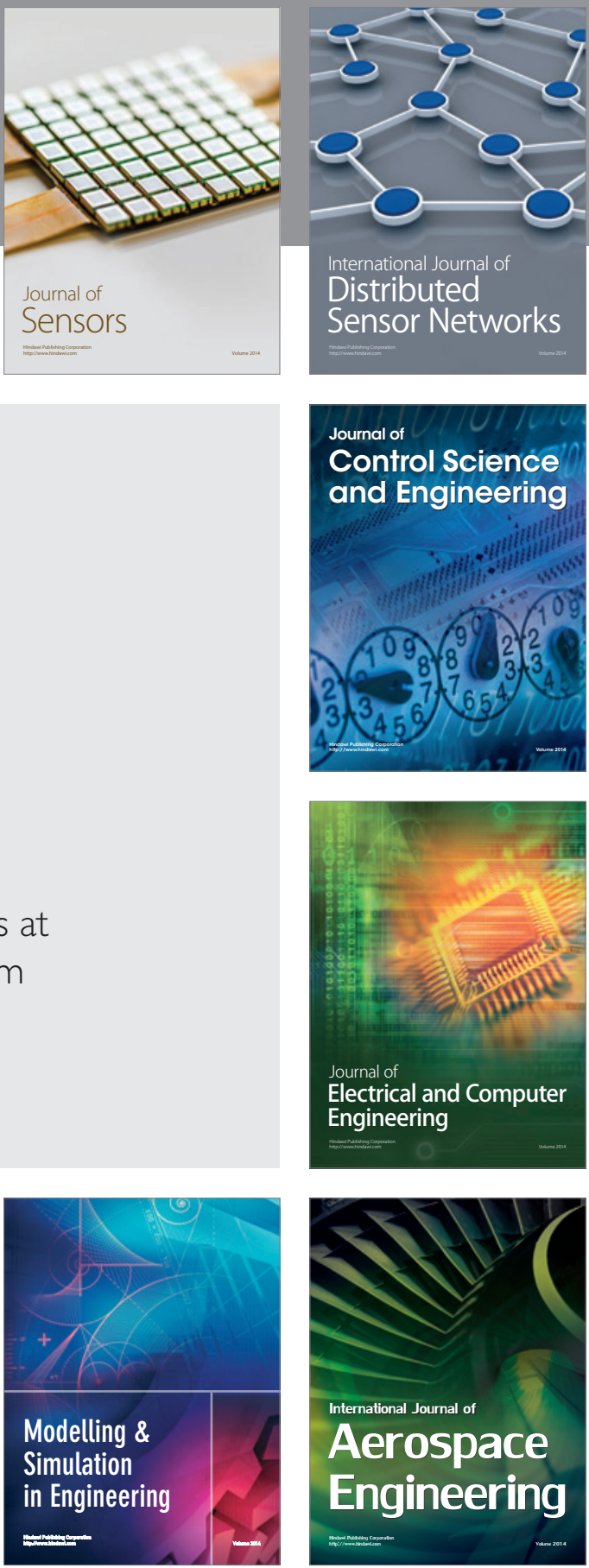

Journal of

Control Science

and Engineering
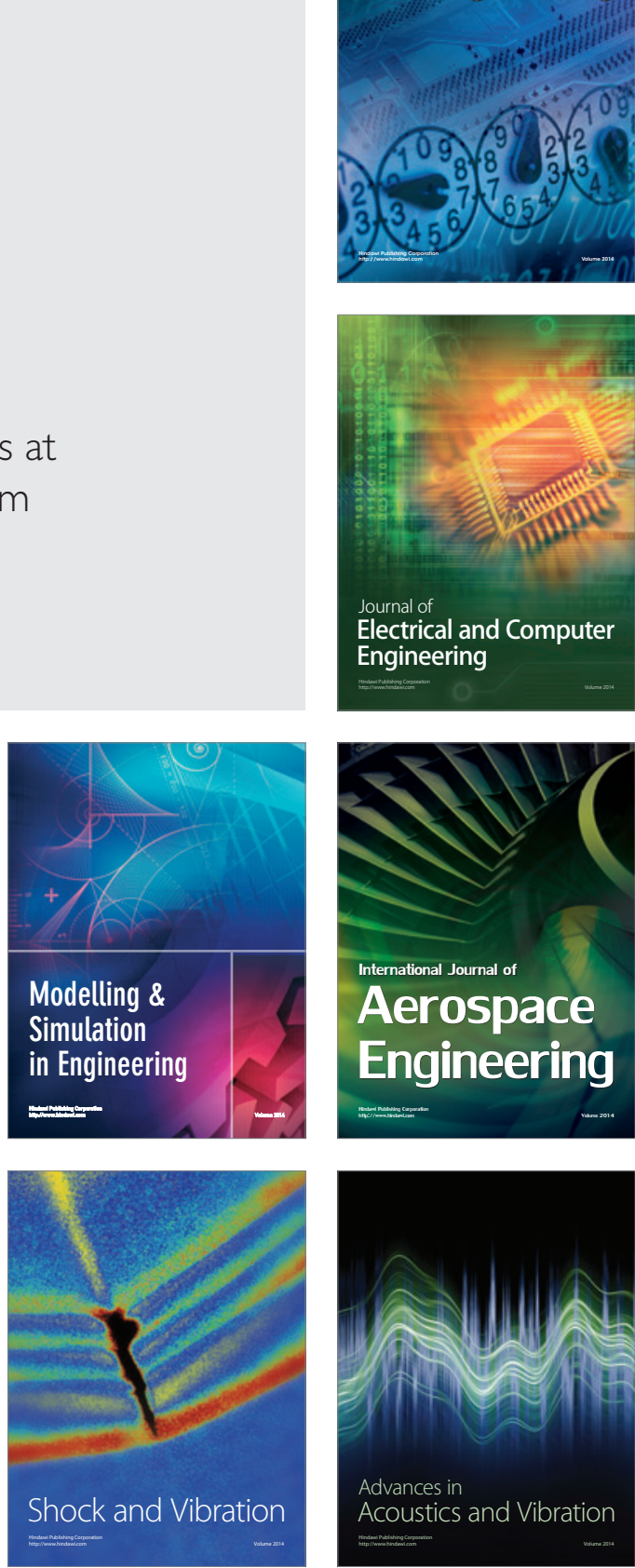